\title{
Platelets and platelet adhesion molecules: novel mechanisms of thrombosis and anti-thrombotic therapies
}

\author{
Xiaohong Ruby $\mathrm{Xu}^{1,2,3}$, Naadiya Carrim, ${ }^{2,4}$, Miguel Antonio Dias Neves², Thomas McKeown², Tyler W. Stratton², \\ Rodrigo Matos Pinto Coelho ${ }^{2}$, Xi Lei ${ }^{2}$, Pingguo Chen ${ }^{2,4}$, Jianhua Xư ${ }^{5}$, Xiangrong Dai ${ }^{6,7}$, Benjamin Xiaoyi Li $i^{6,7,8}$ \\ and Heyu $\mathrm{Ni}^{1,2,4,5,9^{*}}$
}

From The 9th Congress of the Asian-Pacific Society on Thrombosis and Hemostasis

Taipei, Taiwan. 6-9 October 2016

\begin{abstract}
Platelets are central mediators of thrombosis and hemostasis. At the site of vascular injury, platelet accumulation (i.e. adhesion and aggregation) constitutes the first wave of hemostasis. Blood coagulation, initiated by the coagulation cascades, is the second wave of thrombin generation and enhance phosphatidylserine exposure, can markedly potentiate cell-based thrombin generation and enhance blood coagulation. Recently, deposition of plasma fibronectin and other proteins onto the injured vessel wall has been identified as a new "protein wave of hemostasis" that occurs prior to platelet accumulation (i.e. the classical first wave of hemostasis). These three waves of hemostasis, in the event of atherosclerotic plaque rupture, may turn pathogenic, and cause uncontrolled vessel occlusion and thrombotic disorders (e.g. heart attack and stroke). Current anti-platelet therapies have significantly reduced cardiovascular mortality, however, on-treatment thrombotic events, thrombocytopenia, and bleeding complications are still major concerns that continue to motivate innovation and drive therapeutic advances. Emerging evidence has brought platelet adhesion molecules back into the spotlight as targets for the development of novel anti-thrombotic agents. These potential antiplatelet targets mainly include the platelet receptors glycoprotein (GP) Ib-IX-V complex, $\beta 3$ integrins (allb subunit and PSI domain of $\beta 3$ subunit) and GPVI. Numerous efforts have been made aiming to balance the efficacy of inhibiting thrombosis without compromising hemostasis. This mini-review will update the mechanisms of thrombosis and the current state of antiplatelet therapies, and will focus on platelet adhesion molecules and the novel anti-thrombotic therapies that target them.
\end{abstract}

Keywords: allbß33, Anfibatide, GPIba, GPVI, Hemostasis, Integrins, P-selectin, Stroke, Thrombosis

Abbreviations: ADP, Adenosine diphosphate; GLP-1R, Glucagon-like peptide 1 receptor; GP, Glycoprotein; ITAM, Immunoreceptor tyrosine-based activation motif; ITP, Idiopathic thrombocytopenic purpura; LLR, Leucine-rich repeat; PAR, Protease-activated receptor; PCI, Percutaneous coronary intervention; PDI, Protein disulphide isomerase; PSI, Plexin-semaphorin-integrin; TIA, Transient ischemic attack; TTP, Thrombotic thrombocytopenic purpura; WWF, von Willebrand factor

\footnotetext{
* Correspondence: nih@smh.ca

'Department of Laboratory Medicine and Pathobiology, University of

Toronto, Toronto, ON, Canada

${ }^{2}$ Department of Laboratory Medicine, Keenan Research Centre for Biomedical

Science, St. Michael's Hospital, Toronto, ON, Canada

Full list of author information is available at the end of the article
} 


\section{Background}

Platelet adhesion, activation and aggregation are critical events in hemostasis and thrombosis [1-3]. Platelet adhesion molecules, $\alpha \operatorname{IIb} \beta 3$ integrin and the glycoprotein (GP) Ib-IX-V, are essential for these processes [4-6]. Other adhesion molecules, such as P-selectin, GPVI and cadherins, are also involved [7-10]. The important roles of adhesion molecules in normal hemostasis have been well demonstrated in bleeding disorders, for example, Glanzmann thrombasthenia ( $\beta 3$ integrin deficiency) [11] and Bernard-Soulier syndrome (GPIb-IX-V complex deficiency) [12]. However, under pathological conditions, excessive platelet function may lead to thrombotic diseases, such as myocardial infarction and ischemic stroke, which cause far more deaths each year than cancer or respiratory diseases [1, 2, 13-15]. Therefore, antiplatelet agents are vital for the treatment of thrombosis [16]. For over a decade, dual antiplatelet therapy with clopidogrel and aspirin has been considered a key treatment of patients with acute coronary syndrome [17, 18]. Nonetheless, some patients undergoing this combination therapy continue to suffer from recurrent thrombotic events, likely a result of platelet activation and aggregation occurring independently of ADP or thromboxane A2 receptor-mediated signalling pathways [17]. Thus, attenuating platelet adhesion appears to be a desirable strategy in effectively controlling pathological thrombosis [18]. Further understanding of the interactions between platelet adhesion molecules and their binding partners is therefore crucial in developing novel antithrombotic therapies. This review briefly summarizes the current knowledge of thrombosis and antiplatelet therapies, introduces a number of major platelet adhesion molecules, and highlights some recent advances in the new mechanisms of thrombosis, and anti-thrombotic therapies that are in clinical trials (unless otherwise indicated). There are several excellent available reviews regarding antiplatelet therapies, such as ADP antagonists (e.g. P2Y12 inhibitors), thromboxane antagonists and PAR-1/4 inhibitors $[17,18]$. This mini-review will mainly focus on the therapeutic developments targeting platelet adhesion molecules.

\section{Review}

\section{Arterial thrombosis and current state of antiplatelet therapies}

Arterial thrombosis at the site of atherosclerotic plaque rupture may lead to uncontrolled vessel occlusion, resulting in life-threatening consequences (e.g. unstable angina, myocardial infarction and ischemic stroke) $[1,2,13]$. During plaque rupture, subendothelial matrix proteins, like collagen, von Willebrand factor (VWF), fibrinogen, fibronectin and laminin are exposed to circulation, leading to the rapid response of platelets [6]. Inappropriate platelet adhesion, activation and aggregation promote excessive platelet plug formation. Activated platelets can also provide negatively-charged surfaces that harbor coagulation factors and markedly potentiate cell-based thrombin generation and blood coagulation [1, 2, 19, 20]. The evolving concept of the "protein wave of hemostasis" indicates a potential role of platelet-released plasma fibronectin in thrombosis and hemostasis [21, 22]. Thus, platelets are key mediators of atherothrombosis, which are actively involved in all three waves of thrombus formation: protein wave, platelet accumulation, and blood coagulation [21, 23].

Current FDA-approved antiplatelet therapies (Fig. 1) mainly aim to (i) inhibit thromboxane A2 synthesis, which inhibits platelet activation (e.g. aspirin and triflusal); (ii) antagonize the function of platelet P2Y12 receptors, (e.g. clopidogrel, prasugrel, and ticagrelor); (iii) inhibit platelet integrin $\alpha \operatorname{IIb} \beta 3$ activity, which inhibits platelet aggregation, (e.g. abciximab, eptifibatide, and tirofiban); (iv) inhibit phosphodiesterase, which increases platelet cAMP/cGMP levels (e.g. dipyridamole and cilostazol) [24]. These antiplatelet drugs have significantly reduced cardiovascular deaths. However, limitations of current therapies, such as weak/poor inhibition of platelet function, excessive bleeding, thrombocytopenia and unexpected platelet activation are concerns that drive therapeutic advances $[18,25,26]$. In 2014, the FDA approved Vorapaxar, a novel antagonist of the thrombin receptor protease-activated receptor 1 (PAR1), which reduces the risk of heart attack and stroke in patients with atherosclerosis or peripheral arterial disease [27, 28]. However, Vorapaxar must not be used in patients who have histories of stroke, transient ischemic attack (TIA) or intracranial hemorrhage, since it increases the risk of intracranial bleeding $[28,29]$.

\section{Platelet adhesion molecules in hemostasis and thrombosis: novel mechanisms and therapeutic opportunities}

Platelet adhesion molecules are proteins/receptors on the platelet surface that interact with other cells or the extracellular matrix, including the integrin family (e.g. $\alpha 2 \beta 1, \alpha 5 \beta 1, \alpha 6 \beta 1, \alpha \operatorname{L} \beta 2, \alpha \operatorname{IIb} \beta 3$, and $\alpha v \beta 3)[4,30,31$, the immunoglobulin superfamily (e.g. GPVI, FcyRIIA, ICAM-2, PECAM-1, JAMs and Cadherin 6), the leucinerich repeat family (LRR; e.g. GPIb-IX-V complex), and the C-type lectin receptor family (e.g. P-selectin and CLEC-2), etc. [32-34]. Recent evidence has shown that platelet adhesion molecules play key roles in a variety of pathophysiological processes [23], such as hemostasis and thrombosis $[4,33]$, immune responses [35, 36], inflammation [35-37], atherosclerosis [38-40], lymphatic vessel development [41-44], angiogenesis [45-47], miscarriage $[48,49]$, and tumor metastasis [50-52]. Platelets 


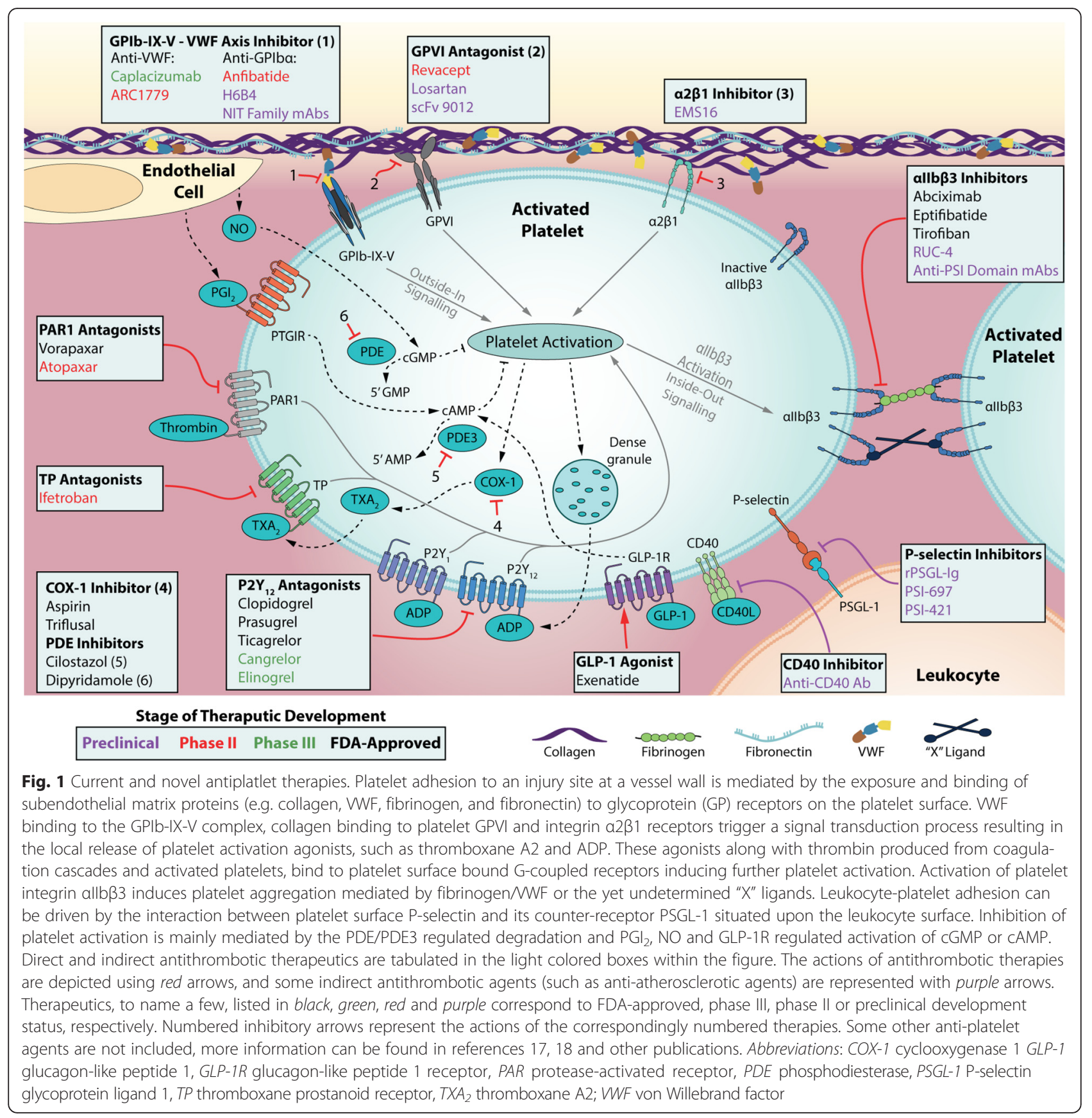

are versatile cells and the mechanisms of their diverse functions have emerged as hot research topics [23]. This review mainly focuses on their roles in thrombosis and as novel anti-thrombotic targets (Fig. 1).

\section{The GPIb-IX-V complex: emerging targets of antiplatelet therapy}

New insights into the GPIb-IX-V complex Platelet GPIb-IX-V complex (LRR family protein) has approximately 50,000 copies/platelet. It is composed of one GPIb $\alpha$ subunit disulfide-linked to two molecules of
GPIb $\beta$, and non-covalently linked with GPIX and GPV in a 2:4:2:1 ratio [53]. GPIb-IX-V is a key platelet receptor in initiating platelet translocation and adhesion to the vessel wall during vascular injury, especially under high shear stress (e.g. in small or stenosed arteries) $[54,55]$. Platelet translocation onto the subendothelium is mediated by the binding of GPIb $\alpha$ to the immobilized VWF, a multimeric adhesive protein secreted from activated endothelial cells and platelets. The crystal structure of the GPIb $\alpha$ Nterminal ligand-binding domain and the VWF A1 domain gives useful information regarding their interaction [56]. 
This interaction induces intracellular signalling events that can activate integrins, leading to platelet stable adhesion and subsequent platelet aggregation. Interestingly, platelet-derived VWF was recently shown not essential for hemostasis and thrombosis, but instead fosters thromboinflammatory diseases such as ischemic stroke in mice via a GPIb-dependent mechanism [57]. This suggests that targeting GPIb $\alpha$-VWF may be a promising anti-thrombotic strategy, particularly in thrombo-inflammatory conditions.

Furthermore, GPIb-IX-V complex has a high affinity for thrombin $[58,59]$. Two thrombin binding sites on GPIb $\alpha$ LRR C-terminal flank region have been revealed [58]. Consequently, thrombin can activate platelets via GPIb $\alpha$ in two ways [60]: accelerating the cleavage of PAR-1 and platelet activation [61], or direct signaling via GPIb $\alpha$, particularly after cleaving GPV, which is generally considered a "brake" in GPIb-IX-V activation $[62,63]$. It is currently unknown but it is reasonable to consider that targeting both VWF and thrombin binding sites of GPIb $\alpha$ might provide additional benefits in effectively controlling thrombosis.

GPIb $\alpha$ can also interact with multiple other ligands, leading to platelet activation (e.g. thrombospondin [64] and P-selectin), pro-coagulant activity (e.g. factors XI [65], XII [66], VIIa [67] and kininogen [68]), inflammatory responses (e.g. P-selectin $\left.[69,70], \alpha_{M} \beta_{2}[71]\right)$, arterial remodeling [72] and others. Recently, the antibodyGPIb interaction in immune thrombocytopenia has been highlighted. Some anti-GPIb $\alpha$ antibodies cause platelet activation and desialylation (removal of sugars), followed by the clearance of desialylated platelets via Ashwell-Morell receptors on hepatocytes $[73,74]$.

\section{Developing novel antiplatelet agents against GPIbo} Given the critical roles of GPIb $\alpha$ or GPIb $\alpha$-VWF interactions in platelet adhesion, particularly under stenosis high-shear conditions, they are attractive targets in attenuating thrombosis $[54,75,76]$. Currently, two such agents are in active clinical trials. ALX-0081 (Caplacizumab), an anti-VWF humanized single-variable-domain immunoglobulin (Nanobody), binds to the A1 domains of VWF with high affinity [77]. The phase I and II clinical trials of ALX-0081 in patients with stable angina undergoing percutaneous coronary intervention (PCI) or high risk PCI patients have shown a promising antiplatelet effects, and a relatively safe profile [77, 78]. The phase III clinical trials will investigate its effects on acquired thrombotic thrombocytopenic purpura (TTP) [79-81]. ARC1779, an anti-VWF aptamer, was previously reported as an encouraging agent; however, the clinical trial of ARC1779 was prematurely terminated [82]. These VWF inhibitors may be useful candidates for TTP treatment.
A direct anti-GPIb $\alpha$ drug, Anfibatide, is purified from the snake venom of Agkistrodon acutus [83, 84]. Notably, Anfibatide inhibits both VWF and $\alpha$-thrombin binding to GPIb $\alpha$, representing a more potent anti-thrombotic effect [85]. In experimental models, Anfibatide inhibited platelet adhesion, aggregation and thrombus formation, without increasing bleeding time [83]. The phase II human clinical trials have also shown the promise of Anfibatide being utilized as a novel antiplatelet agent in cardiovascular diseases without significantly affecting hemostasis in patients with non-ST segment elevation myocardial infarction (unpublished data) [85]. Additionally, anti-GPIb $\alpha$ antibody displayed a strong protective effect in the mouse stroke models without inducing significant intracranial bleeding [86-88]. Anfibatide has also been shown as a candidate to treat ischemic stroke in experimental models [89] (the same may hold true for anti-VWF therapy) and deserves further investigation. There are some other preclinical agents targeting GPIb $\alpha$ that are under investigation, such as h6B4-Fab [90], GPG-290 [91], and anti-GPIb $\alpha$ NIT family monoclonal antibodies [92]. The generation of these novel antagonists is reaching the forefront of treatment against heart attack and stroke, although the efficacy and safety of these drugs remain to be further established or evaluated in human clinical trials. Notably, there are currently no clinically available direct GPIb $\alpha$ antagonists.

\section{GPVI: a potential anti-thrombotic target}

GPVI (immunoglobulin superfamily protein) is exclusively expressed on platelets and megakaryocytes. It is associated with the Fc receptor $\gamma$-chain, which contains an immunoreceptor tyrosine-based activation motif (ITAM). Cross-linking by ligands, such as collagen, leads to ITAM-dependent signalling, and platelet activation. A possible anti-thrombotic benefit of targeting PI3-kinase/ Akt pathway on ITAM receptors was suggested [93]. Fibrin has also been identified as a new GPVI ligand [94]. The GPVI ectodomain interacts with immobilized fibrin, which amplifies thrombin generation, and promotes thrombus stabilization [94, 95].

The role of platelet GPVI in the pathogenesis of ischemic stroke has been gradually acknowledged [96-98]. Notably, platelet adhesion/activation can enhance infarct growth by promoting an inflammatory response $[88,99$, 100]. GPVI-mediated platelet activation can lead to the release of interleukin-1 $\alpha$ that drives cerebrovascular inflammation [100]. GPVI may be thus a potential antiplatelet target [97, 101, 102]. In animal models, anti-GPVI protected against thrombosis, ischemia-reperfusion injury [103] and stroke [104]. In phase I clinical trials, Revacept (the humanized Fc fusion protein of the GPVI ectodomain), inhibited collagen-induced human platelet aggregation [105]. Phase II trials of Revacept in patients with 
carotid artery stenosis, TIA, or stroke are ongoing [106]. The efficacy and safety of Revacept in these patients will be further determined. Some other GPVI targeted agents that are under preclinical development, such as Losartan [107] and scFv9012 [108], have been shown to inhibit the binding of GPVI to collagen.

\section{Platelet integrin receptors}

Integrins are heterodimeric transmembrane receptors, which are involved in cell-cell and cell-matrix interactions [30]. There are six different integrins on platelet surfaces: $\alpha 2 \beta 1, \alpha 5 \beta 1, \alpha 6 \beta 1, \alpha \mathrm{L} \beta 2, \alpha \operatorname{IIb} \beta 3$, and $\alpha v \beta 3$. Platelet integrin $\alpha \operatorname{IIb} \beta 3$ is the dominant integrin expressed on platelets. Given the critical roles of $\alpha \operatorname{IIb} \beta 3$ integrin in mediating platelet aggregation, $\alpha \operatorname{IIb} \beta 3$ antagonists have been widely used for nearly two decades.

Integrin $\alpha \mathrm{IIb} \beta 3$ as anti-thrombotic targets: lessons and opportunities Approximately $17 \%$ of total platelet surface proteins are $\alpha \operatorname{IIb} \beta 3$ integrin, which contains both $\alpha I I b$ and $\beta 3$ subunits [4]. Platelet "outside-in" signals are induced following platelet adhesion and platelet activation (e.g. GPIb $\alpha-V W F, G P V I / \alpha 2 \beta 1$-collagen, P2Y ${ }_{12}$-ADP, PARs-thrombin), resulting in an increased $\mathrm{Ca}^{2+}$ influx and ultimately "inside-out" signaling. These "inside-out" signals further drive the conformational changes of $\alpha \mathrm{IIb} \beta 3$, from a low to high affinity state for binding to its ligands (e.g. fibrinogen/fibrin, VWF, fibronectin, thrombospondin, vitronectin and unidentified " $\mathrm{X}$ " ligands) [109-112].

Fibrinogen, a major prothrombotic ligand of $\alpha \operatorname{IIb} \beta 3$, has been documented to be required for platelet aggregation for over 50 years. However, platelet aggregation still occurs in the absence of fibrinogen and VWF, although in the absence of $\alpha \operatorname{IIb} \beta 3$, aggregation is abolished $[5,8,21,113-116]$. The discovery of "fibrinogen-independent platelet aggregation" demonstrates that unidentified $\alpha \operatorname{IIb} \beta 3$ ligands also mediate platelet aggregation $[5,8,21,113,116]$, and have the potential to be novel anti-thrombotic targets. Interestingly, some ligands (e.g. plasma fibronectin, vitronectin) may block prothrombotic ligand (e.g. fibrinogen)- $\alpha \operatorname{IIb} \beta 3$ interactions and attenuate thrombosis $[21,117]$.

Three FDA-approved $\alpha \operatorname{IIb} \beta 3$ antagonists are available: Abciximab (ReoPro), Eptifibatide (Integrilin) and Tirofiban (Aggrastat) [118-120]. Abciximab is a fragmented antibody that binds close to the ligand binding-pocket on $\alpha \operatorname{IIb} \beta 3$. Eptifibatide, isolated from snake venom, binds via a KGD sequence and is a competitive inhibitor for fibrinogen- $\alpha \operatorname{IIb} \beta 3$, whilst tirofiban is a small molecule RGD inhibitor. Currently, $\alpha \operatorname{IIb} \beta 3$ antagonists are used in patients undergoing PCI and significantly decrease the incidence of myocardial infarction and death [121]. However, these antagonists can induce further conformational changes in the $\beta 3$ subunit that may have negative consequences, such as exposing previously hidden epitopes, and causing platelet activation [122]. $\alpha \operatorname{IIb} \beta 3$ antagonists are also associated with intracranial hemorrhage in patients with acute ischemic stroke [123]. Therefore, a safer and more specific on-target drug is required to provide better patient care. Recently, a novel $\alpha \operatorname{IIb} \beta 3$ antagonist, RUC-4 (a more potent and more soluble congener of RUC-2 that disrupts $\mathrm{Mg}^{2+}$ binding to the metal ion-dependent adhesion site of $\alpha \operatorname{IIb} \beta 3$ ), is suggested for prehospital therapy of myocardial infarction in animal models, without significantly priming the receptor to bind fibrinogen [124]. However, the possibility of increased bleeding with therapeutic doses of RUC-4 remains to be evaluated [124].

The plexin-semaphorin-integrin (PSI) domain, located near the $\mathrm{N}$-terminus of the $\beta 3$ subunit, is highly conserved across the integrin family in different species, and contains seven cysteine residues which have been implicated in regulating $\beta 2$ integrin activation $[125,126]$. Previous studies described a role for cysteine-derived thiol/ disulfide groups in the conformational switches of the $\beta 3$ integrin [127-130]. Disulfide bond remodeling is mediated primarily by thiol isomerase enzymatic activity, which is derived from active CXXC thioredoxin motifs and plays a role in the activation of $\alpha \operatorname{IIb} \beta 3$ [131]. Our group has recently identified that integrin PSI domain has endogenous thiol isomerase function and could be a novel target for anti-thrombotic therapy (unpublished data) [132]. We found that both CXXC motifs of $\beta 3$ integrin PSI domain are required to maintain the optimal enzyme function, since mutations to one or both of the CXXC motifs decrease or abolish their protein disulphide isomerase (PDI)-like activity. We developed anti-PSI monoclonal antibodies and found that these antibodies cross-reacted with $\beta 3$ PSI domains of human and other species and specifically inhibited the PDI-like activity, integrin activation and reduced PAC- 1 binding to $\beta 3$ integrin. Importantly, anti-PSI abrogated murine and human platelet aggregation in vitro and thrombus growth ex vivo and in vivo in both small and large vessels without significantly affecting bleeding time or platelet count. Thus, integrin PSI domain contains endogenous PDI activity and is a key regulator of integrin activation that can be a new target for therapy.

Interestingly, targeting activated platelets $\alpha \operatorname{IIb} \beta 3$ has been considered into the development of novel fibrinolytic drugs, which may allow effective thrombolysis and thromboprophylaxis $[14,133]$. For example, scFvSCE5 (a single-chain urokinase plasminogen activator fused to a small recombinant antibody that binds activated $\alpha \operatorname{IIb} \beta 3$ ) directly targets thrombi and exerts an effective thrombolysis [133]. A chimeric platelet-targeted urokinase prodrug (composed of a single-chain version of the variable 
region of an anti- $\alpha \operatorname{IIb} \beta 3 \mathrm{mAb}$ and a thrombin-activatable, low-molecular-weight pro-uPA) selectively targets new thrombus formation [134].

Other platelet integrins: $\alpha 2 \beta 1, \alpha 6 \beta 1$ and $\alpha 5 \beta 1$ Other integrin receptors may also be considered as novel antithrombotic targets $[16,135]$. Platelet $\alpha 2 \beta 1$ promotes stable platelet adhesion to collagen and may be a viable option, since overexpression of $\alpha 2 \beta 1$ in humans increases atherothrombotic risk, but lower level of $\alpha 2 \beta 1$ does not enhance bleeding risk [16]. Experimental evidence shows that $\alpha 2 \beta 1$ inhibitors (e.g. snake venom EMS-16) reduced pathological thrombus formation in vivo [136-138]. Platelet $\alpha 6 \beta 1$, the main receptor for laminin, plays a role in platelet adhesion/activation and arterial thrombosis, and may also be a new target [135]. Platelet $\alpha 5 \beta 1$, the major receptor for fibronectin, plays a supplementary role in platelet adhesion [139], but evidence is lacking regarding the anti-thrombotic benefits of antagonizing $\alpha 5 \beta 1$.

\section{Other novel anti-thrombotic candidates: Glucagon-like peptide 1 receptor, P-selectin, CD40/CD40L, and Toll-like receptors}

Strategies to target other platelet receptors beyond adhesive proteins have also been developed, such as P2Y12, PAR1, TP, $5 \mathrm{HT}_{2 \mathrm{~A}}$ antagonists $[17,140]$. Interestingly, some chronic diseases, such as diabetes mellitus and atherosclerosis, are associated with arterial thrombosis [23, 141]. Recently, our group identified that a functional Glucagon-like peptide 1 receptor (GLP-1R) is expressed on human megakaryocytes and platelets [142]. Importantly, GLP-1R agonists (e.g. Exenatide), likely through increasing the intracellular cAMP levels, inhibit platelet function and thrombus formation [142]. This study provides important insights into why diabetic patients who are receiving GLP-1-targeted therapies have a reduced number of cardiovascular events [142, 143]. In addition, given the cross-talks between platelets and immune systems, thrombosis also intensively communicates with the inflammatory pathway [23]. Some antiinflammatory/anti-atherosclerotic agents may therefore also indirectly inhibit thrombosis, especially in deep vein thrombosis [144]. For example, antagonists of Pselectin/PSGL-1, such as rPSGL-Ig [145], PSI-697 [146], PSI-421 [147], inhibit platelet-mediated leukocyte attachment and recruitment of procoagulant microparticles, and may represent a safe therapeutic intervention in accelerating thrombolysis [148]. Antagonists of CD40/ CD40L [149], such as CD40 antibody, reduce atherosclerotic burden in a murine model [150]. In addition, as the important roles of Toll-like receptors in atherosclerosis are gradually recognized $[151,152]$, they may also be potential targets for the treatment of atherothrombosis.

\section{Conclusions}

Arterial thrombotic events, such as myocardial infarction and ischemic stroke, and venous thromboembolism, are three leading causes of morbidity and mortality worldwide [153]. Platelets play a central role in the pathogenesis of atherothrombosis, and contribute profoundly to the pathology of venous thrombosis [23]. Platelet adhesion molecules, act as the contacts between platelets and other cells or extracellular matrix proteins and, to a great extent, may determine the reactivity of platelets and thus are attractive anti-thrombotic targets (Fig. 1) [23]. Although evidence-based antiplatelet therapy has markedly improved patient care, on-treatment events and bleeding are still major concerns $[17,148]$.

Optimization of the use of currently available therapies, and improvements to the understanding of individual differences in response to anti-platelet treatments are still the most cost-effective treatment strategies [17, 148]. Additionally, improved understanding of the mechanisms of platelet accumulation has been critical for further developing novel antiplatelet therapies, such as the PAR1 antagonist Vorapaxar (recently approved by the FDA), GPIb $\alpha /$ VWF antagonists (e.g. ALX-0081 and Anfibatide; undergoing clinical trials), and GPVI antagonist (e.g. Revacept; undergoing clinical trials) (See section II. A-C). Another cost-effective strategy may be to repurpose already-established drugs by discovering novel mechanisms of action in anti-thrombotic diseases, such as the recently-identified GLP-1R agonist, Exenatide, an antidiabetic drug that has potential anti-thrombotic effects $[142,154]$. Future studies in the areas of atherothrombosis, inflammation, metabolic syndrome, diabetes, lipid metabolism and cancer-related thrombotic diseases in the next few years should advance our knowledge and the application of these and other new anti-platelet agents. Of note, clinical trials provide important evidence regarding the safety and efficacy of the treatments. However, difficulties such as narrow eligibility criteria, low enrollment of patients and the necessity to test the new drugs on top of the current dual antiplatelet therapy (e.g. aspirin and clopidogrel), may add complexity to the development of new drugs and also deserve our attention.

\section{Acknowledgements \\ The authors would like to thank Dr. Richard O. Hynes, Dr. Zaverio M. Ruggeri, Dr. Denisa D. Wagner, and Dr. John Freedman for their long-term support for} these research projects.

\section{Declaration}

Publication fees for this article have been funded by APSTH 2016. This article has been published as part of Thrombosis Journal Volume 14 Supplement 1, 2016. The full contents of the supplement are available at https://thrombosisjournal.biomedcentral.com/articles/supplements/volume14-supplement-1.

\section{Funding}

This work was supported by the Canadian Institutes of Health Research (MOP 119540, MOP 97918, and MOP 119551), Heart and Stroke Foundation 
of Canada (Ontario), Equipment Funds from Canada Foundation for Innovation, St. Michael's Hospital, and Canadian Blood Services; and research Funds from CCOA Therapeutics Inc and Lee's Pharmaceutical Holdings limited. X. R. X is a recipient of China National Scholarship award, Meredith \& Malcolm Silver Scholarship in Cardiovascular Studies of Department of Laboratory Medicine and Pathobiology, and the Heart and Stroke/Richard Lewar Centre of Excellence Studentship award, University of Toronto. N.C. is a recipient of the Canadian Blood Services Postdoctoral Fellowship.

\section{Availability of data and materia}

Not applicable.

\section{Authors' contributions}

XRX and NC drafted the manuscript. MADN drew the figure. TM, TWS and RMPC contributed to preparation of the manuscript. $\mathrm{XL}, \mathrm{XD}$ and $\mathrm{BXL}$ contributed to the original findings on the phase II human clinical trials of Anfibatide. PC and JX contributed to the original findings and further development of anti-PSI monoclonal antibodies. HN is the principal investigator who defined the topic and revised the manuscript. All of authors read, commented and approved the final manuscript.

\section{Competing interests}

J. X. is supported by the CCOA Therapeutics Inc. X. D. and B.X.L. are supported by the Lee's Pharmaceutical Holdings limited. Some of the research fund of the projects is supported by CCOA Therapeutics and Lee's Pharmaceutical Holdings limited. Canadian Blood Services have held the patents on the anti-GPIb NIT family monoclonal antibodies and anti-PS monoclonal antibodies.

\section{Consent for publication}

Not applicable.

\section{Ethics approval and consent to participate}

Not applicable.

\section{Author details}

${ }^{1}$ Department of Laboratory Medicine and Pathobiology, University of Toronto, Toronto, ON, Canada. ${ }^{2}$ Department of Laboratory Medicine, Keenan Research Centre for Biomedical Science, St. Michael's Hospital, Toronto, ON, Canada. ${ }^{3}$ Guangdong Provincial Hospital of Chinese Medicine, Guangzhou University of Chinese Medicine, Guangzhou, Guangdong, People's Republic of China. ${ }^{4}$ Canadian Blood Services, Toronto, ON, Canada. ${ }^{5} \mathrm{CCOA}$ Therapeutics Inc, Toronto, ON, Canada. 'Lee's Pharmaceutical holdings limited, Shatin, Hong Kong, China. 'Z Zhaoke Pharmaceutical co. limited, Hefei, Anhui, China. ${ }^{8}$ Hong Kong University of Science and technology, Hong Kong, China. ${ }^{9}$ Department of Medicine and Department of Physiology, University of Toronto, Toronto, ON, Canada.

\section{Published: 4 October 2016}

\section{References}

1. Ruggeri ZM. Platelets in atherothrombosis. Nat Med. 2002;8:1227-34.

2. Mackman N. Triggers, targets and treatments for thrombosis. Nature 2008;451:914-8.

3. Xu XR, Gallant RC, Ni H. Platelets, immune-mediated thrombocytopenias, and fetal hemorrhage. Thromb Res. 2016;141 Suppl 2:S76-9.

4. $\mathrm{Ni} \mathrm{H}$, Freedman J. Platelets in hemostasis and thrombosis: role of integrins and their ligands. Transfus Apher Sci. 2003;28:257-64.

5. Yang H, Reheman A, Chen P, Zhu G, Hynes RO, Freedman J, et al. Fibrinogen and von Willebrand factor-independent platelet aggregation in vitro and in vivo. J Thromb Haemost. 2006:4:2230-7.

6. Wang $\mathrm{Y}$, Gallant RC, Ni H. Extracellular matrix proteins in the regulation of thrombus formation. Curr Opin Hematol. 2016;23:280-7.

7. Moroi M, Jung SM, Okuma M, Shinmyozu K. A patient with platelets deficient in glycoprotein VI that lack both collagen-induced aggregation and adhesion. J Clin Invest. 1989:84:1440-5.

8. Dunne E, Spring CM, Reheman A, Jin W, Berndt MC, Newman DK, et al. Cadherin 6 has a functional role in platelet aggregation and thrombus formation. Arterioscler Thromb Vasc Biol. 2012;32:1724-31.
9. Palabrica T, Lobb R, Furie BC, Aronovitz M, Benjamin C, Hsu YM, et al. Leukocyte accumulation promoting fibrin deposition is mediated in vivo by P-selectin on adherent platelets. Nature. 1992;359:848-51.

10. Yang $H$, Lang $S$, Zhai $Z$, Li L, Kahr WH, Chen $P$, et al. Fibrinogen is required for maintenance of platelet intracellular and cell-surface P-selectin expression. Blood. 2009;114:425-36.

11. Nurden AT. Platelet membrane glycoproteins: a historical review. Semin Thromb Hemost. 2014:40:577-84.

12. Lopez JA, Andrews RK, Afshar-Kharghan V, Berndt MC. Bernard-Soulier syndrome. Blood. 1998;91:4397-418.

13. Jackson SP. Arterial thrombosis-insidious, unpredictable and deadly. Nat Med. 2011;17:1423-36.

14. Reheman A, Xu X, Reddy EC, Ni H. Targeting activated platelets and fibrinolysis: hitting two birds with one stone. Circ Res. 2014;114:1070-3.

15. Writing Group Members, Mozaffarian D, Benjamin EJ, Go AS, Arnett DK, Blaha MJ, et al. Heart disease and stroke statistics-2016 update: a report from the American Heart Association. Circulation. 2016;133:e38-60.

16. Michelson AD. Antiplatelet therapies for the treatment of cardiovascular disease. Nat Rev Drug Discov. 2010;9:154-69.

17. Franchi F, Angiolillo DJ. Novel antiplatelet agents in acute coronary syndrome. Nat Rev Cardiol. 2015;12:30-47.

18. Gachet C. Antiplatelet drugs: which targets for which treatments? J Thromb Haemost. 2015;13 Suppl 1:S313-22

19. Hou Y, Carrim N, Wang Y, Gallant RC, Marshall A, Ni H. Platelets in hemostasis and thrombosis: novel mechanisms of fibrinogen-independent platelet aggregation and fibronectin-mediated protein wave of hemostasis. J Biomed Res. 2015;29:437-44.

20. Wang H, Bang KW, Blanchette VS, Nurden AT, Rand ML. Phosphatidylserine exposure, microparticle formation and mitochondrial depolarisation in Glanzmann thrombasthenia platelets. Thromb Haemost. 2014;111:1184-6.

21. Wang $Y$, Reheman A, Spring CM, Kalantari J, Marshall AH, Wolberg AS, et al. Plasma fibronectin supports hemostasis and regulates thrombosis. J Clin Invest. 2014;124:4281-93.

22. Wang $\mathrm{Y}, \mathrm{Ni} \mathrm{H}$. Fibronectin maintains the balance between hemostasis and thrombosis. Cell Mol Life Sci. 2016;73(17):3265-77. doi:10.1007/s00018-016-2225-y.

23. Xu XR, Zhang D, Oswald BE, Carrim N, Wang X, Hou Y, et al. Platelets are versatile cells: New discoveries in hemostasis, thrombosis, immune responses, tumor metastasis and beyond. Crit Rev Clin Lab Sci. 2016. Published online:1-69. doi: 10.1080/10408363.2016.1200008.

24. Metharom P, Berndt MC, Baker Rl, Andrews RK. Current state and novel approaches of antiplatelet therapy. Arterioscler Thromb Vasc Biol. 2015;35:1327-38.

25. Michelson AD. Advances in antiplatelet therapy. Hematology Am Soc Hematol Educ Program. 2011;2011:62-9.

26. Jackson SP, Schoenwaelder SM. Antiplatelet therapy: in search of the 'magic bullet'. Nat Rev Drug Discov. 2003;2:775-89.

27. Morrow DA, Braunwald E, Bonaca MP, Ameriso SF, Dalby AJ, Fish MP, et al. Vorapaxar in the secondary prevention of atherothrombotic events. N Engl Med 2012:366:1404-13.

28. Adminstration USFaD. Drug Trials Snapshot Zontivity (vorapaxar). 2014. http://www.fda.gov/Drugs/InformationOnDrugs/ucm423935.htm. Accessed 15 June 2016

29. ClinicalTrials.gov. 2011. https://clinicaltrials.gov/ct2/show/NCT00527943?term= Vorapaxar\&rank=5. Accessed 15 June 2016.

30. Hynes RO. Integrins: bidirectional, allosteric signaling machines. Cell. 2002;110:673-87.

31. Mou Y, Ni H, Wilkins JA. The selective inhibition of beta 1 and beta 7 integrin-mediated lymphocyte adhesion by bacitracin. J Immunol. 1998;161:6323-9.

32. Clemetson KJ, Clemetson JM. Platelet receptors. In: Michelson AD, editor Platelets. 3rd ed. Amsterdam: Academic Press/Elsevier; 2013. p. 169-94.

33. Varga-Szabo D, Pleines I, Nieswandt B. Cell adhesion mechanisms in platelets. Arterioscler Thromb Vasc Biol. 2008;28:403-12.

34. Tamura S, Suzuki-Inoue K, Tsukiji N, Shirai T, Sasaki T, Osada M, et al. Podoplanin-positive periarteriolar stromal cells promote megakaryocyte growth and proplatelet formation in mice by CLEC-2. Blood. 2016;127:1701-10.

35. Li C, Li J, Li Y, Lang S, Yougbare I, Zhu G, et al. Crosstalk between platelets and the immune system: old systems with new discoveries. Adv Hematol. 2012;2012:384685

36. Semple JW, Italiano Jr JE, Freedman J. Platelets and the immune continuum Nat Rev Immunol. 2011;11:264-74. 
37. Wagner DD, Burger PC. Platelets in inflammation and thrombosis. Arterioscler Thromb Vasc Biol. 2003;23:2131-7.

38. Siegel-Axel D, Daub K, Seizer P, Lindemann S, Gawaz M. Platelet lipoprotein interplay: trigger of foam cell formation and driver of atherosclerosis. Cardiovasc Res. 2008;78:8-17.

39. Lindemann S, Kramer B, Seizer P, Gawaz M. Platelets, inflammation and atherosclerosis. J Thromb Haemost. 2007;5 Suppl 1:203-11.

40. Murphy AJ, Bijl N, Yvan-Charvet L, Welch CB, Bhagwat N, Reheman A, et al. Cholesterol efflux in megakaryocyte progenitors suppresses platelet production and thrombocytosis. Nat Med. 2013;19:586-94.

41. Hess PR, Rawnsley DR, Jakus Z, Yang Y, Sweet DT, Fu J, et al. Platelets mediate lymphovenous hemostasis to maintain blood-lymphatic separation throughout life. J Clin Invest. 2014;124:273-84.

42. Navarro-Nunez L, Langan SA, Nash GB, Watson SP. The physiological and pathophysiological roles of platelet CLEC-2. Thromb Haemost. 2013;109:991-8.

43. Osada M, Inoue $O$, Ding G, Shirai $T$, Ichise $H$, Hirayama $K$, et al. Platelet activation receptor CLEC-2 regulates blood/lymphatic vessel separation by inhibiting proliferation, migration, and tube formation of lymphatic endothelial cells. J Biol Chem. 2012;287:22241-52.

44. Herzog BH, Fu J, Wilson SJ, Hess PR, Sen A, McDaniel JM, et al. Podoplanin maintains high endothelial venule integrity by interacting with platelet CLEC-2. Nature. 2013;502:105-9.

45. Italiano Jr JE, Richardson JL, Patel-Hett S, Battinelli E, Zaslavsky A, Short S, et al. Angiogenesis is regulated by a novel mechanism: pro- and antiangiogenic proteins are organized into separate platelet alpha granules and differentially released. Blood. 2008;111:1227-33.

46. Chatterjee M, Huang Z, Zhang W, Jiang L, Hultenby K, Zhu L, et al. Distinct platelet packaging, release, and surface expression of proangiogenic and antiangiogenic factors on different platelet stimuli. Blood. 2011;117:3907-11.

47. Yougbare I, Lang S, Yang H, Chen P, Zhao X, Tai WS, et al. Maternal anti-platelet beta3 integrins impair angiogenesis and cause intracranial hemorrhage. J Clin Invest. 2015;125:1545-56.

48. Li C, Piran S, Chen P, Lang S, Zarpellon A, Jin JW, et al. The maternal immune response to fetal platelet GPIbalpha causes frequent miscarriage in mice that can be prevented by intravenous $\lg G$ and anti-FcRn therapies. J Clin Invest. 2011;121:4537-47.

49. Yougbare I, Wei-She T, Zdravic D, Chen P, Zhu G, Leong-Poi H, et al. Natural killer cells contribute to pathophysiology of placenta leading to miscarriage in fetal and neonatal alloimmune thrombocytopenia. Blood. 2015;126:2254.

50. Labelle M, Hynes RO. The initial hours of metastasis: the importance of cooperative host-tumor cell interactions during hematogenous dissemination. Cancer Discov. 2012;2:1091-9.

51. Labelle M, Begum S, Hynes RO. Platelets guide the formation of early metastatic niches. Proc Natl Acad Sci U S A. 2014;111:E3053-61.

52. Franco AT, Corken A, Ware J. Platelets at the interface of thrombosis, inflammation, and cancer. Blood. 2015:126:582-8.

53. Luo SZ, Mo X, Afshar-Kharghan V, Srinivasan S, Lopez JA, Li R. Glycoprotein Ibalpha forms disulfide bonds with 2 glycoprotein Ibbeta subunits in the resting platelet. Blood. 2007;109:603-9.

54. Jackson SP. The growing complexity of platelet aggregation. Blood. 2007;109:5087-95.

55. Ruggeri ZM, Mendolicchio GL. Adhesion mechanisms in platelet function. Circ Res. 2007;100:1673-85.

56. Huizinga EG, Tsuji S, Romijn RA, Schiphorst ME, de Groot PG, Sixma JJ, et al. Structures of glycoprotein Ibalpha and its complex with von Willebrand factor A1 domain. Science. 2002;297:1176-9.

57. Verhenne S, Denorme F, Libbrecht S, Vandenbulcke A, Pareyn I, Deckmyn H, et al. Platelet-derived WWF is not essential for normal thrombosis and hemostasis but fosters ischemic stroke injury in mice. Blood. 2015;126:1715-22.

58. Dumas JJ, Kumar R, Seehra J, Somers WS, Mosyak L. Crystal structure of the Gplbalpha-thrombin complex essential for platelet aggregation. Science. 2003;301:222-6.

59. Celikel R, McClintock RA, Roberts JR, Mendolicchio GL, Ware J, Varughese KI, et al. Modulation of alpha-thrombin function by distinct interactions with platelet glycoprotein Ibalpha. Science. 2003;301:218-21.

60. Andrews RK, Berndt MC. The GPIb-IX-V Complex. In: Michelson AD, editor. Platelets. 3rd ed. Amsterdam: Academic Press/Elsevier; 2013. p. 195-213.

61. De Candia E, Hall SW, Rutella S, Landolfi R, Andrews RK, De Cristofaro R. Binding of thrombin to glycoprotein $\mathrm{lb}$ accelerates the hydrolysis of Par-1 on intact platelets. J Biol Chem. 2001;276:4692-8.
62. Ramakrishnan V, DeGuzman F, Bao M, Hall SW, Leung LL, Phillips DR. A thrombin receptor function for platelet glycoprotein Ib-IX unmasked by cleavage of glycoprotein V. Proc Natl Acad Sci U S A. 2001;98:1823-8.

63. Ni H, Ramakrishnan V, Ruggeri ZM, Papalia JM, Phillips DR, Wagner DD. Increased thrombogenesis and embolus formation in mice lacking glycoprotein V. Blood. 2001;98:368-73.

64. Jurk K, Clemetson KJ, de Groot PG, Brodde MF, Steiner M, Savion N, et al. Thrombospondin-1 mediates platelet adhesion at high shear via glycoprotein Ib (GPIb): an alternative/backup mechanism to von Willebrand factor. FASEB J. 2003;17:1490-2.

65. Baglia FA, Badellino KO, Li CQ, Lopez JA, Walsh PN. Factor XI binding to the platelet glycoprotein Ib-IX-V complex promotes factor XI activation by thrombin. J Biol Chem. 2002;277:1662-8.

66. Bradford HN, Pixley RA, Colman RW. Human factor XII binding to the glycoprotein Ib-IX-V complex inhibits thrombin-induced platelet aggregation. J Biol Chem. 2000;275:22756-63.

67. Weeterings C, de Groot PG, Adelmeijer J, Lisman T. The glycoprotein Ib-IX-V complex contributes to tissue factor-independent thrombin generation by recombinant factor VIla on the activated platelet surface. Blood. 2008;112:3227-33

68. Chavakis T, Santoso S, Clemetson KJ, Sachs UJ, Isordia-Salas I, Pixley RA, et al. High molecular weight kininogen regulates platelet-leukocyte interactions by bridging Mac-1 and glycoprotein Ib. J Biol Chem. 2003;278:45375-81.

69. Romo GM, Dong JF, Schade AJ, Gardiner EE, Kansas GS, Li CQ, et al. The glycoprotein Ib-IX-V complex is a platelet counterreceptor for P-selectin. J Exp Med. 1999;190:803-14.

70. Kaplan ZS, Zarpellon A, Alwis I, Yuan Y, McFadyen J, Ghasemzadeh M, et al. Thrombin-dependent intravascular leukocyte trafficking regulated by fibrin and the platelet receptors GPIb and PAR4. Nat Commun. 2015;6:7835

71. Simon DI, Chen Z, Xu H, Li CQ, Dong J, McIntire LV, et al. Platelet glycoprotein ibalpha is a counterreceptor for the leukocyte integrin Mac-1 (CD11b/CD18). J Exp Med. 2000;192:193-204.

72. Chandraratne S, von Bruehl ML, Pagel JI, Stark K, Kleinert E, Konrad I, et al. Critical role of platelet glycoprotein ibalpha in arterial remodeling. Arterioscler Thromb Vasc Biol. 2015;35:589-97.

73. Li J, van der Wal DE, Zhu G, Xu M, Yougbare I, Ma L, et al. Desialylation is a mechanism of Fc-independent platelet clearance and a therapeutic target in immune thrombocytopenia. Nat Commun. 2015;6:7737.

74. Li J, Callum JL, Lin Y, Zhou Y, Zhu G, Ni H. Severe platelet desialylation in a patient with glycoprotein Ib/IX antibody-mediated immune thrombocytopenia and fatal pulmonary hemorrhage. Haematologica. 2014;99:e61-3.

75. Gresele P, Momi S. Inhibitors of the interaction between von Willebrand factor and platelet GPIb/IXN. Handb Exp Pharmacol. 2012;(210):287-309.

76. Ulrichts H, Silence K, Schoolmeester A, de Jaegere P, Rossenu S, Roodt J, et al. Antithrombotic drug candidate ALX-0081 shows superior preclinical efficacy and safety compared with currently marketed antiplatelet drugs. Blood. 2011;118:757-65.

77. Bartunek J, Barbato E, Heyndrickx G, Vanderheyden M, Wijns W, Holz JB. Novel antiplatelet agents: ALX-0081, a Nanobody directed towards von Willebrand factor. J Cardiovasc Transl Res. 2013;6:355-63.

78. Muller O, Bartunek J, Hamilos M, Berza CT, Mangiacapra F, Ntalianis A, et al. von Willebrand factor inhibition improves endothelial function in patients with stable angina. J Cardiovasc Transl Res. 2013;6:364-70.

79. Peyvandi F, Scully M, Kremer Hovinga JA, Cataland S, Knobl P, Wu H, et al. Caplacizumab for acquired thrombotic thrombocytopenic purpura. N Engl J Med. 2016;374:511-22.

80. Lammle B. Thrombotic microangiopathy: caplacizumab accelerates resolution of acute acquired TTP. Nat Rev Nephrol. 2016;12:259-60.

81. Von VA. Willebrand factor-a new target for TTP treatment? N Engl J Med. 2016;374:583-5

82. Blombery P, Scully M. Management of thrombotic thrombocytopenic purpura: current perspectives. J Blood Med. 2014;5:15-23.

83. Lei $X$, Reheman A, Hou Y, Zhou H, Wang Y, Marshall AH, et al. Anfibatide, a novel GPIb complex antagonist, inhibits platelet adhesion and thrombus formation in vitro and in vivo in murine models of thrombosis. Thromb Haemost. 2014;111:279-89.

84. Hou Y, Li BX, Dai X, Yang Z, Qian F, Zhang G, et al. The first in vitro and in vivo assessment of anfibatide, a novel glycoprotein ib antagonist, in mice and in a phase i human clinical trial. Blood. 2013;122:577. 
85. Li B, Dai X, Yang Z, Qian F, Zhang G, Xu Z, et al. First ex vivo and in vivo assessment of anfibatide, a novel glycoprotein Ib-IV-V complex antagonist, in healthy human volunteers in phase I clinical trial. J Thromb Haemost. 2013;11 Suppl 2:23.

86. Nieswandt B, Kleinschnitz C, Stoll G. Ischaemic stroke: a thromboinflammatory disease? J Physiol. 2011:589:4115-23.

87. Stoll G, Kleinschnitz C, Nieswandt B. Molecular mechanisms of thrombus formation in ischemic stroke: novel insights and targets for treatment. Blood. 2008;1 12:3555-62

88. Kleinschnitz C, Pozgajova M, Pham M, Bendszus M, Nieswandt B, Stoll G. Targeting platelets in acute experimental stroke: impact of glycoprotein $\mathrm{lb}$, $\mathrm{Vl}$, and IIb/IIla blockade on infarct size, functional outcome, and intracranial bleeding. Circulation. 2007;115:2323-30.

89. Li TT, Fan ML, Hou SX, Li XY, Barry DM, Jin H, Luo SY, Kong F, Lau LF, Dai $X R$, Zhang GH, Zhou LL. A novel snake venomderived GPlb antagonist, anfibatide, protects mice from acute experimental ischaemic stroke and reperfusion injury. Br J Pharmacol.

90. Fontayne A, Meiring M, Lamprecht S, Roodt J, Demarsin E, Barbeaux P, et al. The humanized anti-glycoprotein Ib monoclonal antibody h6B4-Fab is a potent and safe antithrombotic in a high shear arterial thrombosis model in baboons. Thromb Haemost. 2008;100:670-7.

91. Hennan JK, Swillo RE, Morgan GA, Leik CE, Brooks JM, Shaw GD, et al. Pharmacologic inhibition of platelet $v W F-G P I b$ alpha interaction prevents coronary artery thrombosis. Thromb Haemost. 2006;95:469-75.

92. $\mathrm{Ni} \mathrm{H}$, Zhu G. Novel monoclonal antibodies against platelet GPIb-alpha: potential anti-thrombotic drugs and research reagents for study of thrombosis and hemostasis. 2012. US8323652.

93. Moroi AJ, Watson SP. Impact of the PI3-kinase/Akt pathway on ITAM and hemITAM receptors: haemostasis, platelet activation and antithrombotic therapy. Biochem Pharmacol. 2015;94:186-94.

94. Alshehri OM, Hughes CE, Montague S, Watson SK, Frampton J, Bender M, et al. Fibrin activates GPVI in human and mouse platelets. Blood. 2015;126:1601-8.

95. Mammadova-Bach E, Ollivier V, Loyau S, Schaff M, Dumont B, Favier R, et al. Platelet glycoprotein $\mathrm{VI}$ binds to polymerized fibrin and promotes thrombin generation. Blood. 2015;126:683-91.

96. Bigalke B, Stellos K, Geisler T, Kremmer E, Seizer P, May AE, et al. Expression of platelet glycoprotein $\mathrm{VI}$ is associated with transient ischemic attack and stroke. Eur J Neurol. 2010;17:111-7.

97. Induruwa I, Jung SM, Warburton EA. Beyond antiplatelets: the role of glycoprotein VI in ischemic stroke. Int J Stroke. 2016. doi:10.1177/ 1747493016654532.

98. Al-Tamimi M, Gardiner EE, Thom JY, Shen Y, Cooper MN, Hankey GJ, et al. Soluble glycoprotein VI is raised in the plasma of patients with acute ischemic stroke. Stroke. 2011;42:498-500.

99. Stoll G, Kleinschnitz C, Nieswandt B. Combating innate inflammation: a new paradigm for acute treatment of stroke? Ann N Y Acad Sci. 2010;1207:149-54.

100. Thornton P, McColl BW, Greenhalgh A, Denes A, Allan SM, Rothwell NJ. Platelet interleukin-1alpha drives cerebrovascular inflammation. Blood. 2010; 115:3632-9.

101. Stegner D, Haining EJ, Nieswandt B. Targeting glycoprotein VI and the immunoreceptor tyrosine-based activation motif signaling pathway. Arterioscler Thromb Vasc Biol. 2014;34:1615-20.

102. Dutting S, Bender M, Nieswandt B. Platelet GPVI: a target for antithrombotic therapy?! Trends Pharmacol Sci. 2012;33:583-90.

103. Pachel C, Mathes D, Arias-Loza AP, Heitzmann W, Nordbeck P, Deppermann C, et al. Inhibition of platelet GPVI protects against myocardial ischemiareperfusion injury. Arterioscler Thromb Vasc Biol. 2016;36:629-35.

104. Goebel S, Li Z, Vogelmann J, Holthoff HP, Degen H, Hermann DM, et al. The GPVI-FC fusion protein Revacept improves cerebral infarct volume and functional outcome in stroke. PLoS One. 2013:8:e66960.

105. Ungerer M, Rosport K, Bultmann A, Piechatzek R, Uhland K, Schlieper $P$, et al. Novel antiplatelet drug revacept (Dimeric Glycoprotein VI-Fc) specifically and efficiently inhibited collagen-induced platelet aggregation without affecting general hemostasis in humans. Circulation. 2011;123:1891-9.

106. ClinicalTrials.gov. 2015. https://clinicaltrials.gov/ct2/show/ NCT01645306?term= Revacept\&rank=1. Accessed 15 June 2016.

107. Ono K, Ueda H, Yoshizawa Y, Akazawa D, Tanimura R, Shimada I, et al. Structural basis for platelet antiaggregation by angiotensin II type 1 receptor antagonist losartan (DuP-753) via glycoprotein VI. J Med Chem 2010;53:2087-93.

108. Muzard J, Bouabdelli M, Zahid M, Ollivier V, Lacapere JJ, Jandrot-Perrus M, et al. Design and humanization of a murine scFv that blocks human platelet glycoprotein VI in vitro. FEBS J. 2009;276:4207-22.

109. Takagi J, Petre BM, Walz T, Springer TA. Global conformational rearrangements in integrin extracellular domains in outside-in and inside-out signaling. Cell. 2002;110:599-611.

110. Li R, Mitra N, Gratkowski H, Vilaire G, Litvinov R, Nagasami C, et al. Activation of integrin alphallbbeta3 by modulation of transmembrane helix associations. Science. 2003;300:795-8.

111. Vinogradova O, Vaynberg J, Kong X, Haas TA, Plow EF, Qin J. Membranemediated structural transitions at the cytoplasmic face during integrin activation. Proc Natl Acad Sci U S A. 2004;101:4094-9.

112. Vinogradova $O$, Velyvis A, Velyviene A, Hu B, Haas T, Plow E, et al. A structural mechanism of integrin alpha(llb)beta(3) "inside-out" activation as regulated by its cytoplasmic face. Cell. 2002;110:587-97.

113. $\mathrm{Ni} \mathrm{H}$, Denis CV, Subbarao S, Degen $J$, Sato TN, Hynes RO, et al. Persistence of platelet thrombus formation in arterioles of mice lacking both von Willebrand factor and fibrinogen. J Clin Invest. 2000;106:385-92.

114. Law DA, DeGuzman FR, Heiser P, Ministri-Madrid K, Killeen N, Phillips DR. Integrin cytoplasmic tyrosine motif is required for outside-in alphallbbeta3 signalling and platelet function. Nature. 1999:401:808-11.

115. Hodivala-Dilke KM, McHugh KP, Tsakiris DA, Rayburn H, Crowley D, Ullman-Cullere $M$, et al. Beta3-integrin-deficient mice are a model for Glanzmann thrombasthenia showing placental defects and reduced survival. J Clin Invest. 1999;103:229-38.

116. Reheman A, Yang H, Zhu G, Jin W, He F, Spring CM, et al. Plasma fibronectin depletion enhances platelet aggregation and thrombus formation in mice lacking fibrinogen and von Willebrand factor. Blood. 2009;113:1809-17.

117. Reheman A, Gross $P$, Yang $H$, Chen $P$, Allen $D$, Leytin $V$, et al. Vitronectin stabilizes thrombi and vessel occlusion but plays a dual role in platelet aggregation. J Thromb Haemost. 2005;3:875-83.

118. Topol EJ, Byzova TV, Plow EF. Platelet GPIllb-llla blockers. Lancet. 1999;353:227-31.

119. Phillips DR, Scarborough RM. Clinical pharmacology of eptifibatide. Am J Cardiol. 1997:80:11B-20B

120. Egbertson MS, Chang CT, Duggan ME, Gould RJ, Halczenko W, Hartman GD, et al. Non-peptide fibrinogen receptor antagonists. 2. Optimization of a tyrosine template as a mimic for Arg-Gly-Asp. J Med Chem. 1994;37:2537-51.

121. Schneider DJ. Anti-platelet therapy: glycoprotein IIb-IIla antagonists. Br J Clin Pharmacol. 2011;72:672-82.

122. Coller BS. alphallbbeta3: structure and function. J Thromb Haemost. 2015;13 Suppl 1:S17-25.

123. Ciccone A, Motto C, Abraha I, Cozzolino F, Santilli I. Glycoprotein Ilb-Illa inhibitors for acute ischaemic stroke. Cochrane Database Syst Rev. 2014;3:CD005208.

124. Li J, Vootukuri S, Shang Y, Negri A, Jiang JK, Nedelman M, et al. RUC-4: a novel alphallbbeta3 antagonist for prehospital therapy of myocardial infarction. Arterioscler Thromb Vasc Biol. 2014;34:2321-9.

125. Xiong JP, Stehle T, Goodman SL, Arnaout MA. A novel adaptation of the integrin PSI domain revealed from its crystal structure. J Biol Chem. 2004;279:40252-4.

126. Zang Q, Springer TA. Amino acid residues in the PSI domain and cysteine-rich repeats of the integrin beta2 subunit that restrain activation of the integrin alpha(X)beta(2). J Biol Chem. 2001;276:6922-9.

127. $\mathrm{Ni} \mathrm{H}$, Li A, Simonsen N, Wilkins JA. Integrin activation by dithiothreitol or $\mathrm{Mn} 2+$ induces a ligand-occupied conformation and exposure of a novel $\mathrm{NH} 2$-terminal regulatory site on the beta1 integrin chain. J Biol Chem. 1998; 273:7981-7.

128. Yan B, Smith JW. A redox site involved in integrin activation. J Biol Chem. 2000:275:39964-72.

129. Essex DW, Li M. Redox control of platelet aggregation. Biochemistry. 2003; 42:129-36.

130. Manickam N, Ahmad SS, Essex DW. Vicinal thiols are required for activation of the alphallbbeta3 platelet integrin. J Thromb Haemost. 2011;9:1207-15.

131. Wang L, Wu Y, Zhou J, Ahmad SS, Mutus B, Garbi N, et al. Platelet-derived ERp57 mediates platelet incorporation into a growing thrombus by regulation of the alphallbbeta3 integrin. Blood. 2013;122:3642-50.

132. Carrim N, Zhu G, Reddy E, Xu M, Xu X, Wang Y, et al. Integrin PSI domain has endogenous thiol isomerase function and is a novel target for antithrombotic therapy. J Thromb Haemost. 2015;13(Supplement S2):60. 
133. Wang X, Palasubramaniam J, Gkanatsas Y, Hohmann JD, Westein E, Kanojia $R$, et al. Towards effective and safe thrombolysis and thromboprophylaxis: preclinical testing of a novel antibody-targeted recombinant plasminogen activator directed against activated platelets. Circ Res. 2014;114:1083-93.

134. Fuentes RE, Zaitsev S, Ahn HS, Hayes V, Kowalska M, Lambert MP, et al. A chimeric platelet-targeted urokinase prodrug selectively blocks new thrombus formation. J Clin Invest. 2016;126:483-94.

135. Schaff M, Tang C, Maurer E, Bourdon C, Receveur N, Eckly A, et al. Integrin alpha6beta1 is the main receptor for vascular laminins and plays a role in platelet adhesion, activation, and arterial thrombosis. Circulation. 2013;128:541-52.

136. Miller MW, Basra S, Kulp DW, Billings PC, Choi S, Beavers MP, et al. Small-molecule inhibitors of integrin alpha2beta1 that prevent pathological thrombus formation via an allosteric mechanism. Proc Natl Acad Sci U S A. 2009;106:719-24

137. Marcinkiewicz C, Lobb RR, Marcinkiewicz MM, Daniel JL, Smith JB, Dangelmaier C, et al. Isolation and characterization of EMS16, a C-lectin type protein from Echis multisquamatus venom, a potent and selective inhibitor of the alpha2beta1 integrin. Biochemistry. 2000;39:9859-67.

138. Arlinghaus FT, Momic T, Ammar NA, Shai E, Spectre G, Varon D, et al. Identification of alpha2beta1 integrin inhibitor VP-i with anti-platelet properties in the venom of Vipera palaestinae. Toxicon. 2013;64:96-105.

139. Piotrowicz RS, Orchekowski RP, Nugent DJ, Yamada KY, Kunicki TJ. Glycoprotein Ic-lla functions as an activation-independent fibronectin receptor on human platelets. J Cell Biol. 1988;106:1359-64.

140. Przyklenk K, Frelinger 3rd AL, Linden MD, Whittaker P, Li Y, Barnard MR, et al. Targeted inhibition of the serotonin 5HT2A receptor improves coronary patency in an in vivo model of recurrent thrombosis. J Thromb Haemost. 2010;8:331-40.

141. Ni H. The platelet "sugar high" in diabetes. Blood. 2012;119:5949-51.

142. Cameron-Vendrig A, Reheman A, Siraj MA, Xu XR, Wang Y, Lei X, et al. Glucagon-like peptide 1 receptor activation attenuates platelet aggregation and thrombosis. Diabetes. 2016;65:1714-23.

143. Monami M, Dicembrini I, Nardini C, Fiordelli I, Mannucci E. Effects of glucagon-like peptide-1 receptor agonists on cardiovascular risk: a meta-analysis of randomized clinical trials. Diabetes Obes Metab. 2014;16:38-47.

144. Martinod K, Wagner DD. Thrombosis: tangled up in NETs. Blood. 2014;123:2768-76

145. Kumar A, Villani MP, Patel UK, Keith Jr JC, Schaub RG. Recombinant soluble form of PSGL-1 accelerates thrombolysis and prevents reocclusion in a porcine model. Circulation. 1999;99:1363-9.

146. Bedard PW, Clerin V, Sushkova N, Tchernychev B, Antrilli T, Resmini C, et al. Characterization of the novel P-selectin inhibitor PSI-697 [2-(4-chlorobenzyl)3-hydroxy-7,8,9,10-tetrahydrobenzo[h] quinoline-4-carboxylic acid] in vitro and in rodent models of vascular inflammation and thrombosis. J Pharmacol Exp Ther. 2008;324:497-506.

147. Meier TR, Myers Jr DD, Wrobleski SK, Zajkowski PJ, Hawley AE, Bedard PW, et al. Prophylactic P-selectin inhibition with PSI-421 promotes resolution of venous thrombosis without anticoagulation. Thromb Haemost. 2008;99:343-51.

148. Kolandaivelu K, Bhatt DL. Novel antiplatelet therapies. In: Michelson AD, editor. Platelets. 3rd ed. Amsterdam: Academic Press/Elsevier; 2013. p. 1185-213.

149. Conde ID, Kleiman NS. Soluble CD40 ligand in acute coronary syndromes. N Engl J Med. 2003;348:2575-7.

150. Schonbeck U, Libby P. CD40 signaling and plaque instability. Circ Res. 2001; 89:1092-103.

151. Lin J, Kakkar V, Lu X. Essential roles of toll-like receptors in atherosclerosis. Curr Med Chem. 2016;23:431-54.

152. Hovland A, Jonasson L, Garred P, Yndestad A, Aukrust P, Lappegard KT, et al. The complement system and toll-like receptors as integrated players in the pathophysiology of atherosclerosis. Atherosclerosis. 2015;241:480-94.

153. Beckman MG, Hooper WC, Critchley SE, Ortel TL. Venous thromboembolism: a public health concern. Am J Prev Med. 2010;38:S495-501.

154. Husain M, Aameron-Vendrig A, Ni H. Methods for inhibiting platelet aggregation using glp-1 receptor agonists. Google Patents; 2014. W02014066992.

\section{Submit your next manuscript to BioMed Central and we will help you at every step:}

- We accept pre-submission inquiries

- Our selector tool helps you to find the most relevant journal

- We provide round the clock customer support

- Convenient online submission

- Thorough peer review

- Inclusion in PubMed and all major indexing services

- Maximum visibility for your research

Submit your manuscript at www.biomedcentral.com/submit

) Biomed Central 